\title{
Fast Rate Production of Biodiesel from Neem Seed Oil Using a Catalyst Made from Banana Peel Ash Loaded with Metal Oxide $\left(\mathrm{Li}-\mathrm{CaO} / \mathrm{Fe}_{2}\left(\mathrm{SO}_{4}\right)_{3}\right)$
}

\author{
Ismail J. Madai, ${ }^{1,2,3}$ Yusufu Abeid Chande Jande ${ }^{\mathbb{D}},{ }^{1,3}$ and Thomas Kivevele ${ }^{1 D}{ }^{1,3}$ \\ ${ }^{1}$ Department of Materials and Energy Science and Engineering, \\ The Nelson Mandela African Institution of Science and Technology, P.O. Box 447, Arusha, Tanzania \\ ${ }^{2}$ Department of School Quality Assurance, Ministry of Education, Science and Technology, Dodoma, Tanzania \\ ${ }^{3}$ Water Infrastructure and Sustainable Energy Futures (WISE-Futures), \\ The Nelson Mandela African Institution of Science and Technology, P.O. Box 9124, Nelson Mandela, Arusha, Tanzania \\ Correspondence should be addressed to Yusufu Abeid Chande Jande; yusufu.jande@nm-aist.ac.tz
}

Received 26 April 2020; Accepted 9 July 2020; Published 27 August 2020

Academic Editor: Alicia E. Ares

Copyright ( $\odot 2020$ Ismail J. Madai et al. This is an open access article distributed under the Creative Commons Attribution License, which permits unrestricted use, distribution, and reproduction in any medium, provided the original work is properly cited.

\begin{abstract}
Biodiesel is a possible remedy to the present toxic, finite sources and ever-diminishing crude fuels. Nonedible and locally available (Azadirachta indica) neem seed oil (NSO) as a second-generation feedstock was transformed into biodiesel using calcined banana ash (CBA) derived from banana peels blended with lithium calcium oxide iron (III) sulphate $\mathrm{Li}-\mathrm{CaO} / \mathrm{Fe}_{2}\left(\mathrm{SO}_{4}\right)_{3}$ catalyzed transesterification. Transesterification process was employed to minimize the free fatty acid (FFA) content of NSO to afford $99.8 \%$ yield under the condition of the reaction oil/methanol ratio $8: 1$, followed by addition of $1.7 \%$ wt calcined banana peels ash and $1.3 \%$ wt $\mathrm{Li}-\mathrm{CaO} / \mathrm{Fe}_{2}\left(\mathrm{SO}_{4}\right)_{3}$ catalysts in $53 \mathrm{~min}$, a notable time. It is important to note that the physicochemical properties of biodiesel in this study such as initial boiling points, flash point, pour point, cloud point, density, kinematic viscosity, final boiling points, and cetane index met ASTM D-6751 and EN 14214 standards. Decomposition profile of CBA was displayed by thermal gravimetric analysis (TGA), whereas in-depth analysis by scanning electron microscope (SEM), X-ray diffraction (XRD), X-ray fluorescence (X-RF), and Fourier-transform infrared spectroscopy (FT-IR) revealed that the high efficiency displayed by a catalyst from banana ash calcined at $650^{\circ} \mathrm{C}$ was due to the presence of potassium carbonate $\left(\mathrm{K}_{2} \mathrm{CO}_{3}\right)$, a calcium magnesium silicate $\left(\mathrm{CaMgSiO}_{4}\right)$, and potassium sodium sulphate $\left(\mathrm{KNaSO}_{4}\right)$ contents that accounted for the high basicity of up to 11.09. Additionally, the nitrogen adsorption/desorption studies revealed that CBA interestingly exhibits a high BET surface area of $411.2 \mathrm{~m}^{2} / \mathrm{g}$ and promising mesopores $(3.014 \mathrm{~nm})$. The catalyst also displayed better recyclability evidenced by the fact that it was able to be reused after five successive runs with better recyclability of $75 \%$. Based on the aforementioned properties, this work, therefore, opens an avenue for developing a supreme heterogeneous catalyst from available banana peels ash.
\end{abstract}

\section{Introduction}

The current rate of depletion of fossil fuels accompanied by environmental pollution justifies the need for scientists to divert their attention to green and environmentally compatible energy sources. As one of the most targeted sources of energy, biodiesel has shown its supremacy by its ability to undergo degradation and it is also a renewable, affordable, and environmentally friendly source of energy [1]. Having been reported that direct use of plant oil can cause engine problems such as incomplete combustion, high carbon deposit on the combustion chamber, valve seat, and injector nozzle, therefore, biodiesel is a better option to curb these problems as shown by Ahmad et al. [2]. Transesterification is the main method that has been used in the production of biodiesel as shown by Meher et al. [3]. It is a reaction between oil and alcohol (methanol/ethanol) giving out compounds known as alkyl-esters (methyl/ethyl) accompanied by glycerol as a waste product as shown by Ghadge and Raheman [4]. The intact reaction minimizes parameters 
such as density, molecular weight, and viscosity and even draws its volatility close to that of diesel fuel by Coniglio et al. [5].

For instance, oil from rapeseed (Ramos et al. [6]), soya beans (Gui et al. [7]), sunflower (Antolın [8]), and palm (Crabbe et al. [9]) has gained attention. Unfortunately, the use of edible oils poses a risk in food security and therefore, the current research trends are targeting nonedible oils as the second generation of biodiesel feedstock (Barnwal and Sharma [10]). Various nonedible seeds including neem seed, jatropha, croton, and castor beans have been studied and show good performance in biodiesel production (Atabani et al. [11]). Neem seeds are derived from unique neem trees that have a long lifespan estimated to lie between 150 and 200 years (Schmutterer [12]). It can bear fruits within 3 to 5 years and attains maximum productivity after 10 years and its oil content varies from 30 to $35 \%$ and from 35 to $40 \%$ for kernels and seeds, respectively (Kaura et al. [13]). These properties necessitate thinking of it as a suitable feedstock for biodiesel production. It is given that 7 to $8 \mathrm{~kg}$ of neem seed produces one litre of oil. It is also worth mentioning in this work that planting of neem trees will address not only energy challenges but also environmental challenges (Kumar and Navaratnam [14]).

Various researches including but not limited to banana peels as biomass precursors for biodiesel production have been conducted. For instance, Betiku et al. [15] researched on Napoleon's plumule oil using banana (species Musa gros michel) peels $\mathrm{CBA}$ calcined at $700^{\circ} \mathrm{C}$ for 4 hours with $58.812 \%$ potassium composition and $\mathrm{Fe}_{2}\left(\mathrm{SO}_{4}\right)_{3}$ as a catalyst; the efficiency for biodiesel yield was $98.05 \%$ for 69 -minute reaction time with $2 \mathrm{wt} \%$ catalyst dosage. Similarly, Gohain et al. [16] used CBA from banana (species Musa paradisiacal) plantain peel from West Africa calcined at $700^{\circ} \mathrm{C}$ for 4 hours with $51.02 \%$ potassium composition as a catalyst alongside waste cooking oil and produced $96.3 \%$ of biodiesel for 60 -minute reaction time with $7.6 \mathrm{wt} \%$ catalyst dosage.

The previous application of banana peels as a catalyst for biodiesel production tends to be a slow, time-consuming, large dosage of catalyst usage and large waste disposal. This is due to low potassium content as well as low basic strength which resulted from high calcined of $\mathrm{CBA}$ at $700^{\circ} \mathrm{C}$ which is close to the melting point $\left(740^{\circ} \mathrm{C}\right)$ of potassium oxide $[15,16]$. This calcination may lead to the reaction to take longer time and hence a large dosage of catalyst usage and large waste production. The efficiency of basic contents determines the time for the production of biodiesel.

The common species of banana with high availability in Arusha Tanzania as well as East Africa is Musa acuminata Colla. These banana species are used as food but their peels are treated as wastes $[17,18]$. These peels have high potassium contents which can be used as a biocatalyst for biofuel production [19]. However, using these peels will increase banana production as well as solving the energy problem.

On top of that, this leads to come up with loading metal oxide $\mathrm{Li}-\mathrm{CaO} / \mathrm{Fe}_{2}\left(\mathrm{SO}_{4}\right)_{3}$ to $\mathrm{CBA}$ biocatalyst which forms a strong basic catalyst that increases the oxidation by converting free fatty acid to methyl esters and the performance of the catalyst as well as catalyst reusability. These make the catalyst to be more efficient and stand for an environmentally compatible catalyst for hastening biodiesel production as a possible substitute fuel raw material.

\section{Materials and Methods}

2.1. Materials. The ripe banana peels were sourced from the Tengeru market in Arusha, Tanzania. The reagents used were methanol $\left(\mathrm{CH}_{3} \mathrm{OH}\right)$ 99.8\%, ethanol $\left(\mathrm{C}_{2} \mathrm{H}_{5} \mathrm{OH}\right)$ absolute, iron (III) sulphate $\left(\mathrm{Fe}_{2}\left(\mathrm{SO}_{4}\right)_{3}\right)$, lithium metal (Li), calcium oxide $(\mathrm{CaO})$, phenolphthalein (POP) indicator, hydrochloric acid ( $\mathrm{HCl}) 37 \%$, and Wijis and iodine solution. All chemicals were supplied by Sigma-Aldrich and were used without further modification.

2.2. Preparation of $C B A$. Ripe banana peels were sliced into small pieces to accelerate the drying process. After washing with distilled water, banana peels were sundried for 7 days (turned from yellow to black colour; became light in weight, hard, and wrinkled) followed by oven-drying at $100^{\circ} \mathrm{C}$ for $6 \mathrm{~h}$. Then, the dried banana peels were ashed in a box muffle furnace in the presence of air and finally milled and sieved to a fine powder. The resulting fine ash was annealed in varying temperatures at $100^{\circ} \mathrm{C}$ interval from 550 to $1050^{\circ} \mathrm{C}$ for $3 \mathrm{~h}$ to remove impurities [16]. Finally, the calcined ripe banana peel ash was ground and kept in a seal for further analysis.

2.3. Preparation of Heterogeneous Catalyst. Calcined banana ash was tested for basicity by dissolving $5 \mathrm{~g}$ of CBA/Li-CaO/ $\mathrm{Fe}_{2}\left(\mathrm{SO}_{4}\right)_{3}$ blends in $50 \mathrm{~mL}$ of distilled water using $\mathrm{pH}$ meter. The blended catalyst metal oxide $\mathrm{Li}-\mathrm{CaO} / \mathrm{Fe}_{2}\left(\mathrm{SO}_{4}\right)_{3} / \mathrm{CBA}$ was prepared using $1.3 \mathrm{wt} \%$ of lithium calcium oxide $(\mathrm{Li}-$ $\mathrm{CaO})$ /iron (III), sulphate $\left(\mathrm{Fe}_{2}\left(\mathrm{SO}_{4}\right)_{3}\right)$, and $1.7 \mathrm{wt} \%$ of $\mathrm{CB}$ [1]. Then, $80 \mathrm{~mL}$ of methanol was measured using a measuring cylinder and poured in a conical flask. The blended catalyst was dissolved in methanol with continuous stirring of $2700 \mathrm{rpm}$ within $5 \mathrm{~min}$. Then, the solution of the blended catalyst was ready and finally waited for further activity.

\subsection{Characterization of the Heterogeneous Catalyst.} Micrometrics instruments (ASP2020) were employed for nitrogen sorption studies. Functional groups in the sample such as calcined banana ash were analyzed by using Fouriertransform infrared (FT-IR) instrument. The model of FT-IR used in this study was Alpha Bruker ATR, the wavenumber ranging from 4000 to $1000 \mathrm{~cm}^{-1}$, and XRF for elemental analysis composition. Thermogravimetric analysis was used to show the decomposition profile of the sample. Approximately, $0.24 \mathrm{mg}$ of the sample was subjected to a temperature range from $29^{\circ} \mathrm{C}$ to $800^{\circ} \mathrm{C}$ in a time interval of 5.38 to $78.48 \mathrm{~min}$. TGA gives a clear indication that the calcined temperature should start at $650^{\circ} \mathrm{C}$. Finally, the ground catalyst precursor was subjected to heat treatment in a box furnace for $3 \mathrm{~h}$ at $650^{\circ} \mathrm{C}$. 
2.5. Neem Seed Oil Preparation. Neem seeds were purchased from Bagamoyo, Iringa, and Singida regions in Tanzania. Initially, the seeds were washed with distilled water and then sundried for five days to remove moisture content, whereas other solid dirty impurities were removed by handpicking and winnowing processes [20]. Seeds were soaked in water for $24 \mathrm{~h}$ to remove husks and finally pressed using a hydraulic pressing machine to obtain the oil.

2.6. Biodiesel Production through Transesterification Process. Transesterification process of NSO to biodiesel (methyl esters) was carried out using $1.7 \mathrm{wt} \%$ of CBA loaded with $\mathrm{Li}$ $\mathrm{CaO} / \mathrm{Fe}_{2}\left(\mathrm{SO}_{4}\right)_{3}, 100 \mathrm{~mL}$ methanol, and $800 \mathrm{~mL}$ of NSO. The blended catalyst $\left(1.7 \mathrm{wt} \% \mathrm{CBA} / \mathrm{Li}-\mathrm{CaO} / \mathrm{Fe}_{2} \quad\left(\mathrm{SO}_{4}\right)_{3}\right)$ was mixed with $100 \mathrm{~mL}$ of methanol with continuous stirring at $2700 \mathrm{rpm}$ for five minutes, which was finally followed by addition into $800 \mathrm{~mL}$ of NSO (warmed to $40^{\circ} \mathrm{C}$ ) with continuous stirring until two immiscible layers of biodiesel (top layer) and glycerol (bottom layer) were formed. This reaction was performed in $2000 \mathrm{~mL}$ conical flask and took 53 min. The conical flask was covered with aluminium foil and temperature was monitored by a thermometer under a constant temperature of $60^{\circ} \mathrm{C}$; above this temperature, methanol will be boiled which will reduce the production of biodiesel [21]. The experiment was carried in a water bath until two immiscible layers of biodiesel (top layer) and glycerol (bottom layer) were formed [22]. This transesterification reaction takes place in alcoholic condition (methanol) as the media for the reaction to take place in presence of catalyst which speeds up the reaction but remains unchanged at the end of the reaction [23]. Both separating funnel and filtration methods were employed to isolate the catalyst from the reaction mixture and finally, the filtrate was washed and dried with anhydrous sodium sulphate [24]. The process was repeated using the same filtrate catalyst up to the fifth run. The transesterification process was repeated by varying catalyst dosage from 1 to $1.7 \mathrm{wt} \%$ and methanol-to-oil molar ratio varies from $2: 1$ to 16 . Finally, biodiesel produced was tested using phenolphthalein indicator where the colour changes from clear to pink at a $\mathrm{pH}$ of 8-9 and the universal indicator was also used where the colour changes from green to dark green at $\mathrm{pH}$ of 8-9. However, the percentage of biodiesel yield was calculated by weighing the mass of biodiesel produced over the mass of oil used times hundred [25]. This was calculated using

percentage biodiesel yield $=\frac{\text { weight of biodiesel obtained }}{\text { weight of oil used }} \times 100$.

2.7. Characterization of Biodiesel Properties. Fatty acid composition analysis for NSO was done using Gas Chromatography-Mass Spectrometry (GC-MS), Anton Paar Stabinger viscometer SVM 4001, and density meter DMI 5000. Anton Paar.com instruments were used to determine kinematic viscosity at $40^{\circ} \mathrm{C}$ and density of biodiesel at $15.5^{\circ} \mathrm{C}$ per ASTM D7042 standards. Pour point and cloud point were determined by test cabinet instruments, PSL Systemtechnik/product/pour point tester 45150 and ASTM D2500 cloud point testing. The flashpoint was determined with the aid of Pensky-Martens flash point tester, PMA 5, AntonPaar.com instruments as per ASTM D93 standards. The approximation of various values of acid, iodine, and saponification was done through the titration method.

2.8. Recyclability of the Catalyst. Heterogeneous catalysts have gained fame as compared to homogeneous catalysts because of their reusability [26]. Therefore, the recyclability of the catalyst synthesized in this study was determined as follows. Methanol was used to wash the catalyst spent in the biodiesel production to remove the contents of glycerol and oil. Since water is a product of the transesterification process, the catalyst was later oven-dried for $2 \mathrm{~h}$ at a temperature of $110^{\circ} \mathrm{C}$. After drying and cooling, the spent catalyst was successfully used to produce biodiesel for the next successive run. Biodiesel yield produced was calculated after every successful run till the fifth run.

\section{Results and Discussions}

\subsection{Characterization of the Catalyst}

3.1.1. Thermogravimetric Analysis (TGA). Figure 1 shows the TGA graph with plateaus at $650^{\circ} \mathrm{C}$, a clear indication that all the impurities have been lost and mostly only the metal oxides such as $\mathrm{CaO}, \mathrm{K}_{2} \mathrm{CO}_{3} \mathrm{MgO}$, and $\mathrm{Na}_{2} \mathrm{O}$ remained which increase the performance of the catalyst [27]. Above $740^{\circ} \mathrm{C}$, most of the metal oxides like potassium were decomposed which decrease the basicity and, thus, decrease catalyst performance [28].

3.1.2. Textural Properties. For structural identification of CBA loaded with $\mathrm{Li}-\mathrm{CaO} / \mathrm{Fe}_{2}\left(\mathrm{SO}_{4}\right)_{3}$ which was characterized, the BET method was used to determine the surface area, while Barret-Joyner Halenda (BJH) method was used to determine pore sizes and pore volume. $\mathrm{CBA} \mathrm{Li}-\mathrm{CaO} /$ $\mathrm{Fe}_{2}\left(\mathrm{SO}_{4}\right)_{3}$ blends possess a BET surface of $411 \mathrm{~m}^{2} / \mathrm{g}$, pore diameter of $3.0 \mathrm{~nm}$, and pore volume of $0.628 \mathrm{~cm}^{3} / \mathrm{g}$. According to previous studies on BET and $\mathrm{BJH}$ method in structural identification, CBA possesses a BET surface of $4 \mathrm{~m}^{2} /$ $\mathrm{g}$, pore diameter of $18 \mathrm{~nm}$, and pore volume of $0.02 \mathrm{~cm}^{3} / \mathrm{g}$ (Betiku et al. [15]). According to Gohain et al. [16], CBA possesses a BET surface of $14 \mathrm{~m}^{2} / \mathrm{g}$, pore diameter of $0.6 \mathrm{~nm}$, and pore volume of $0.065 \mathrm{~cm}^{3} / \mathrm{g}$. The CBA Li-CaO/Fe $2\left(\mathrm{SO}_{4}\right)_{3}$ complex shows the large surface area as urged with results obtained by Zabeti et al. [29]. The CBA/Li-CaO/Fe $2\left(\mathrm{SO}_{4}\right)_{3}$ contributed to an increase in performance and reusability of the catalyst due to its high basic contents with a $\mathrm{pH}$ of 11.1. This implies that specific surface area, as well as the pore volume, reusability, and high basic strength, may have a significant contribution to the performance of the catalyst.

3.1.3. FT-IR Spectra Analysis. FT-IR spectra of banana ashes loaded with metal oxide $\mathrm{Li}-\mathrm{CaO} / \mathrm{Fe}_{2}\left(\mathrm{SO}_{4}\right)_{3}$ were characterized as illustrated in Figures 2(a)-2(c) and compared to 


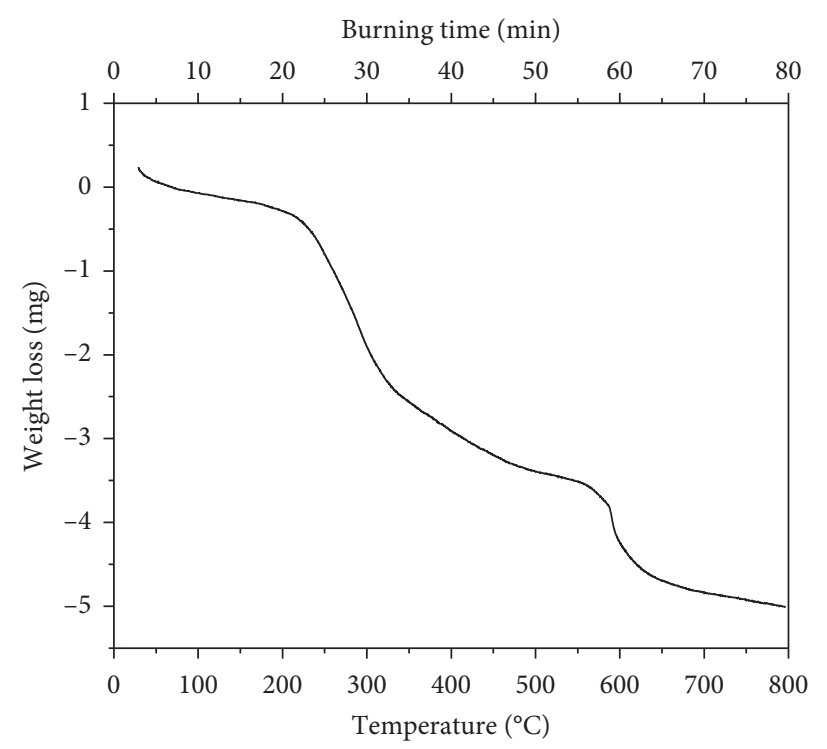

Figure 1: Decomposition profile of catalyst between 29 and $800^{\circ}$.

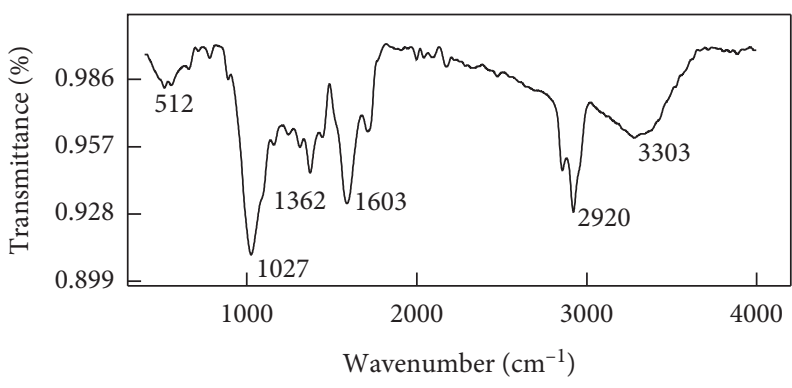

(a)

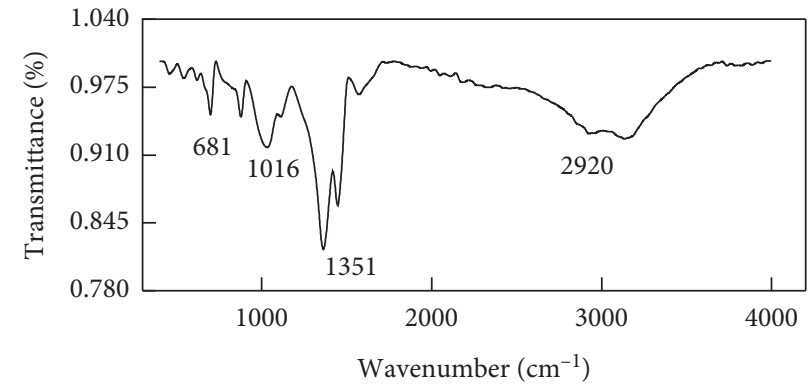

(b)

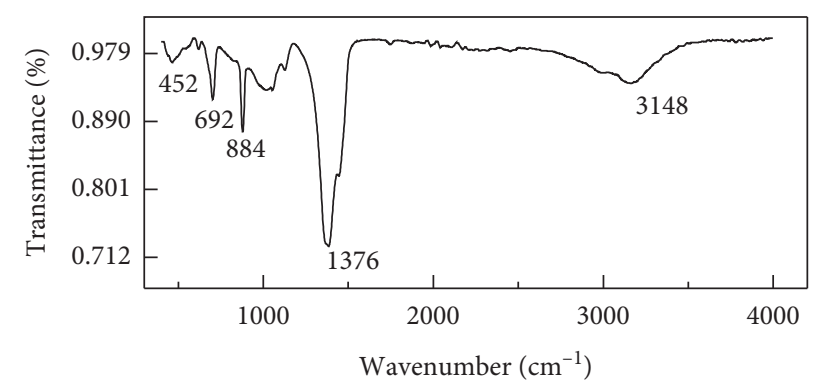

(c)

Figure 2: FT-IR peaks of banana ashes blends: (a) fresh banana ash blends, (b) burnt banana ash blends, and (c) calcined banana as blends.

each other. The broadband at $3303 \mathrm{~cm}^{-1}$ in Figure 2(a) shows the stretching vibration of the $\mathrm{O}-\mathrm{H}$ group and in Figures 2(b) and 2(c), the O-H group disappeared due to burning in air and calcination at $650^{\circ} \mathrm{C}$. The sharp peak and small peak observed at $2920 \mathrm{~cm}^{-1}$ in Figure 2(a) and $2900-3150 \mathrm{~cm}^{-1}$ in Figures 2(b) and 2(c), respectively, show the stretching vibration of the $\mathrm{C}-\mathrm{H}$. Bands observed at $1350-1380 \mathrm{~cm}^{-1}$ have been associated with stretching vibrations of C-O from carbonate which show similarity with wavenumber [30]. The bending vibrations observed at $500-1020 \mathrm{~cm}^{-1}$ show some elements of interest since the peaks are associated with $\mathrm{CaMgSiO}_{4}, \mathrm{Li}_{2} \mathrm{O}$, and $\mathrm{FeSO}_{4}$. It is worth mentioning that a well-pronounced peak of $\mathrm{K}_{2} \mathrm{CO}_{3}$ located at $1376 \mathrm{~cm}^{-1}$ is of special interest given that $\mathrm{K}_{2} \mathrm{CO}_{3}$ comes with several advantages such as increased catalyst performance, surface area, and reusability and prevents leaching as reported elsewhere [15].

3.1.4. Morphological Analysis. A scanning electron microscope displays images at a magnification of $5000 \times$ resolution. The micrographs are shown in Figures 3(a)-3(c) which represent fresh banana ash blends, burnt banana ash blends, and calcined banana ash blends. The surface of Figure 3(a) 


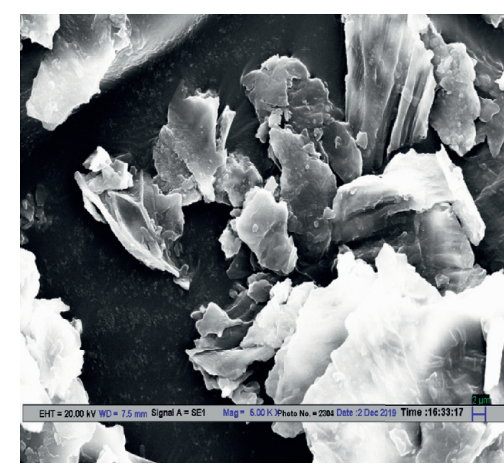

(a)

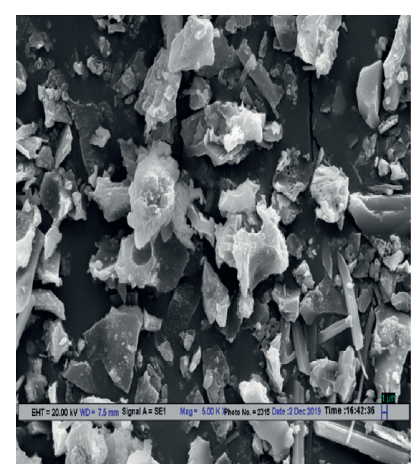

(b)

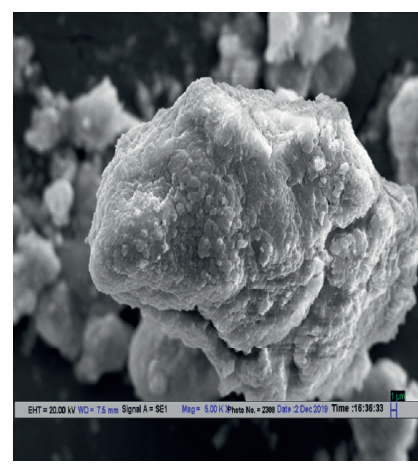

(c)

Figure 3: SEM images of (a) fresh banana ash blends, (b) burnt banana ash blends, and (c) calcined banana ash blends.

shows a smooth and flat nature of fresh banana ash blends, while Figure 3(b) has a mixture of small flake-like aggregates, and lastly Figure 3(c) displays interestingly sponge-like microstructure, a clear indicator of increased surface area which is proportional to the activity of the catalyst. This is in line with the argument of Sharma and his group who observed that heat treatment hinders leaching of $\mathrm{K}$ and, therefore, increases the life of the catalyst [31].

\subsubsection{XRD Analysis. For crystallographic identification,} XRD analysis was carried out on calcined banana ash (CBA) blends, burnt banana ash (BBA) blends, and fresh banana ash (FBA) blends as shown in Figures 4(a)-4(c). There was a significant increase in potassium compounds with an increase in calcination temperature up to $650^{\circ} \mathrm{C}$ as shown in Figure 3(a). Sharp pronounced peaks at 20:29 degrees correspond to $\mathrm{K}_{2} \mathrm{CO}_{3}$, whereas peaks at $2 \theta: 33$ and 43 degrees correspond to $\mathrm{CaMgSiO}_{4}$ and $\mathrm{KNaSO}_{4}$, respectively. Remarkable crystallinity of the materials can be observed from the fact that the peaks are narrow with high intensity. Additionally, weak unmarked peaks in Figures 3(a)-3(c) may be attributed to trace elements like $\mathrm{Fe}_{2}\left(\mathrm{SO}_{4}\right)_{3}$ and $\mathrm{Li}_{2} \mathrm{O}$ which have been reported to have a significant contribution to basicity and consequently optimize the catalyst performance (Betiku et al. [32]).

3.1.6. Elemental Composition of CBA. Table 1 shows that the results of the XRF analysis carried on banana ashes calcined at different temperatures ranged from 550 to $1050^{\circ} \mathrm{C}$ and finally loaded with $\mathrm{Li}-\mathrm{CaO} / \mathrm{Fe}_{2}\left(\mathrm{SO}_{4}\right)_{3}$. These results show the elemental composition present in banana ash. Main elements present in banana ash complex after sample analysis were $\mathrm{K}, \mathrm{Na}, \mathrm{Ca}, \mathrm{Mg}, \mathrm{Fe}, \mathrm{Al}, \mathrm{Si}, \mathrm{S}, \mathrm{Li}$, and $\mathrm{Cl}$. Potassium is the element of interest which has shown highest percentage $(74.4 \%)$ composition after calcination at $650^{\circ} \mathrm{C}$; the ash produced at $650^{\circ} \mathrm{C}$ was used as a catalyst for rapid production of biodiesel.

2.2. Physicochemical Properties of NSO

The physicochemical results were shown in Table 2. The amount of oil in one kilogram of neem seeds was $37.28 \%$ which was enough for the high production of biodiesel. From the following results, the concentration of acid value was reasonably high, suggesting that there was a high level of free fatty acid contents that probably would result in soap formation [11]. For oils with FFA contents higher than 1.1\%, it is desirable to apply a biomass catalyst to maximize the yield of biodiesel production as this may prevent the reaction that results in soap formation [33]. The physicochemical identification of NSO like acid value and saponification value as well as iodine value was done through titration process in line with the agreements of American Society for Testing and Materials (ASTM) in the year 1983 and recommended the practice of official methods of American Oil Chemists Society (AOCS) [34].

The weight of oil extracted from a given mass in grams of seed pressed was measured to determine the lipid contents. The results were expressed as the percentage of oil in the dry matter [35]:

$$
\begin{aligned}
& \text { percentage of oil in sample } \\
& \quad=\frac{\text { weight of dry seed }- \text { weight of residue }}{\text { weight of seed after dry }} .
\end{aligned}
$$

The acid value (AV) of neem oil was determined by titration method, diethyl ether, ethanol (95\%), and phenolphthalein indicator, and a given mass oil sample in the mixture was titrated with $0.1 \mathrm{M} \mathrm{NaOH}$ in triplicate of experiments. The AV was calculated using the following equation [36]:

acid value

$$
=\frac{\text { titre volume } \times \text { grams of } \mathrm{NaOH} \text { in } 0.1 \mathrm{M} \text { of } \mathrm{NaOH} \text { solution }}{\text { sample weight in grams }} .
$$

Iodine value (IV) is the measure of the degree of unsaturation of an oil or fat. Determination of IV in neem seed oil was carried out using laboratory titration method where a given mass of dry soil sample was mixed with a given volume of carbon tetrachloride, Wijis reagent $10 \%$, potassium iodide solution, and distilled water to make a solution and titrate with $0.1 \mathrm{~N}$ of $\left(\mathrm{Na}_{2} \mathrm{~S}_{2} \mathrm{O}_{3}\right)$ sodium thiosulphate solution. The iodine value for the oil in the solution is calculated using the following equation [21]: 

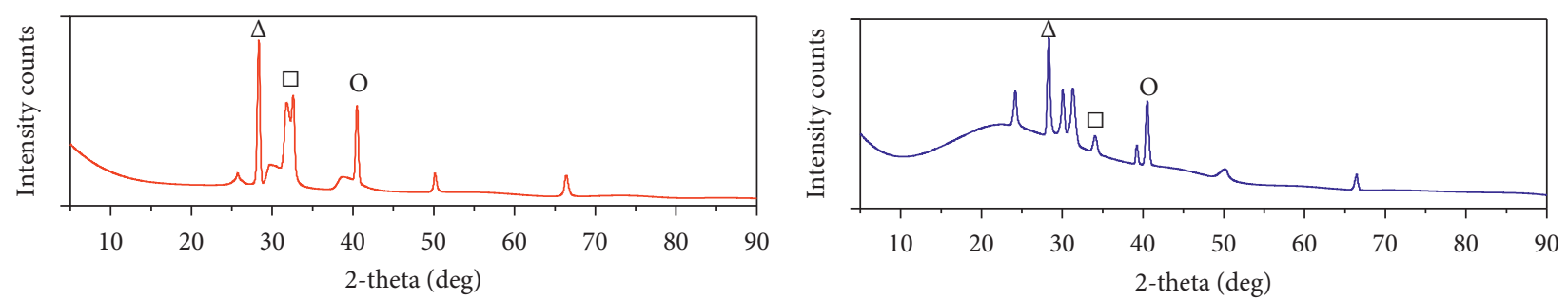
$\triangle \mathrm{K}_{2} \mathrm{CO}_{3}$
$\square \mathrm{CaMgSiO}_{4}$
O $\mathrm{KNaSO}_{4}$
$\Delta \mathrm{K}_{2} \mathrm{CO}_{3}$
$\square \mathrm{CaMgSiO}_{4}$
$\mathrm{O} \mathrm{KNaSO}_{4}$

(a)

(b)

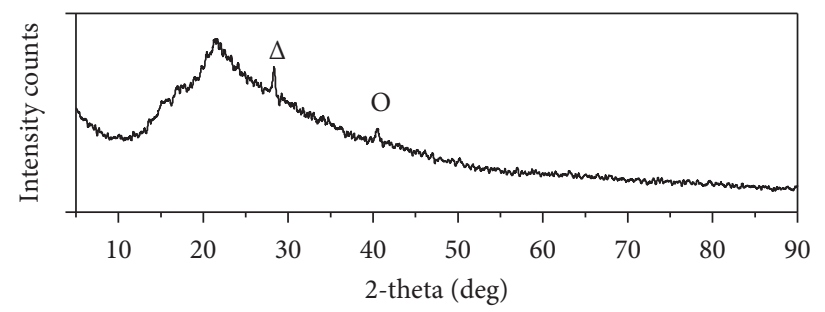

$\Delta \mathrm{K}_{2} \mathrm{CO}_{3}$
$\mathrm{O} \mathrm{KNaSO}_{4}$

(c)

FIGURE 4: XRD pattern of (a) calcined banana ash blends, (b) burnt banana ash blends, and (c) fresh banana ash blends.

TABLE 1: Elemental composition of CBA blends.

\begin{tabular}{lcccccccccc}
\hline Temp $\left({ }^{\circ} \mathrm{C}\right)$ & $\mathrm{K}$ & $\mathrm{Cl}$ & $\mathrm{Si}($ wt.\%) & $\mathrm{Na}$ & $\mathrm{S}$ & $\mathrm{Li}$ & $\mathrm{Al}$ & $\mathrm{Mg}$ & $\mathrm{Ca}$ & $\mathrm{Fe}$ \\
\hline 550 & 54.65 & 7.37 & 4.955 & 3.21 & 3.15 & 1.84 & 1.49 & 1.42 & 1.27 & 0.14 \\
650 & 74.41 & 10.88 & 5.22 & 2.88 & 0.00 & 2.96 & 0.21 & 1.19 & 1.62 & 0.25 \\
750 & 72.51 & 11.36 & 5.79 & 3.79 & 0.00 & 3.02 & 0.18 & 0.70 & 1.68 & 0.28 \\
850 & 72.34 & 7.0 & 9.53 & 3.86 & 0.00 & 2.94 & 1.51 & 0.41 & 1.21 & 0.35 \\
950 & 63.08 & 3.19 & 20.34 & 3.33 & 0.057 & 2.27 & 1.88 & 1.40 & 2.39 & 0.83 \\
1050 & 67.06 & 0.92 & 16.15 & 4.49 & 0.39 & 3.17 & 1.11 & 1.55 & 3.22 & 0.64 \\
\hline
\end{tabular}

TABLE 2: Physicochemical properties of NSO.

\begin{tabular}{lcc}
\hline Property & Unit & NSO \\
\hline Oil content & $\%$ & 37.28 \\
Acid value & $\mathrm{mgKOH} / \mathrm{g}$ & 0.46 \\
Iodine value & $\mathrm{gI}_{2} / 100 \mathrm{~g}$ & 81.06 \\
Saponification value & $\mathrm{mgKOH} / \mathrm{g}$ & 134.8 \\
Free fatty acid (FFA) & $\mathrm{mgKOH} / \mathrm{g}$ & 0.23 \\
\hline
\end{tabular}

$\mathrm{I} . \mathrm{V}=\frac{(b-a) \times \text { mass of iodine in } 0.1 \mathrm{~N} \text { of sodium thiosulphate }}{\text { sample weight in grams }}$

where $a$ and $b$ are average titration volumes $(\mathrm{ml})$ of blank and oil solution and $\mathrm{N}$ is the normality of sodium thiosulphate.

The saponification value (SV) of neem seed oil was determined by titrating a given mass of oil dissolved in a given volume of ethanolic potassium hydroxide $(0.5 \mathrm{M}$ in 95\% ethanol) heated for one hour and then phenolphthalein indicator was added to the sample and then titrated with 0.5 $\mathrm{MHCl}$. The saponification value was calculated using the following equation [37]:

$$
\mathrm{S} . \mathrm{V}=\frac{(b-a) \times \text { grams of } \mathrm{KOH} \text { in } 0.5 \mathrm{M} \mathrm{KOH} \text { solution }}{\text { sample weight in grams }},
$$

where $a$ indicates volume of oil solution and $b$ indicates volume of titre of the blank solution [38]. One has

$$
\text { free fat acid }=\frac{\text { acid value }}{2}
$$

3.1.7. Fatty Acid Profile of Neem Oil. Table 3 shows that neem oil was extremely unsaturated $(67.62 \%)$ due to the availability of linoleic acid, pentadecanoic acid, oleic acid, and linolenic acid as the major methyl esters. Literature reports that methyl esters from neem oil are extremely unsaturated [39]. 
3.2. Characterization of Biodiesel. The properties of biodiesel produced from blends of $\mathrm{CBA} / \mathrm{Li}-\mathrm{CaO} / \mathrm{Fe}_{2} \quad\left(\mathrm{SO}_{4}\right)_{3}$ are summarized in Table 4. Interestingly, these properties show similarities with the standards specified in EN 14214 and ASTM D 6751. For instance, the close similarity in cloud pour points, viscosity, initial boiling points, final boiling points, and acid value was observed. With an exception of density which was slightly higher than the recommended range, all other properties were per the ASTM D6751 standards. However, this biodiesel produced displayed remarkable cold flow properties like cloud point, pour point, and kinematic viscosity and may be used in cold areas. Also, the calorific value was high. It has been reported in the literature that both the molecular mass of methyl ester and its saturation level determine the density of biofuel; in short, the unsaturation level is directly proportional to the specific gravity [40]. The high density of biodiesel from neem oil may be due to the high unsaturation level. It is important to note that partial combustion has been reported because of the poor atomization process from the fact that denser fuels are less compressible [11]. Flashpoint as one of the most important parameters in the diesel engine can be defined as a minimum temperature at which fuel ignites [20]. In this study, it was about $150{ }^{\circ} \mathrm{C}$. This temperature not only meets the required ASTM D6751 standards, which recommends a minimum of $130{ }^{\circ} \mathrm{C}$, but also guarantees safety especially during storage and transportation [41]. The produced biodiesel and catalyst from this study show high yield compared to other studies as reported in Table 4 .

Table 5 shows several precursors including but not limited to banana peels that have been investigated as biomass precursors for biodiesel production. For instance, Betiku et al. [15] researched on banana peel using Napoleon's plumule oil and produced biodiesel $98.5 \%$ for 69 minute reaction time. In a similar study conducted by Gohain et al. [16], banana peel as a catalyst was used alongside waste cooking oil and it produces a biodiesel $96.3 \%$ for 60 -minute reaction time. This study now reveals that $\mathrm{CBA} / \mathrm{Li}-\mathrm{CaO} / \mathrm{Fe}_{2}(\mathrm{SO} 4)_{3}$ blended catalyst is anticipated to reduce the reaction time in the production of biodiesel $98.8 \%$ for 53 -minute reaction time. Therefore, the blended catalyst is economical for the production of biodiesel from NSO as a possible alternative fuel feedstock in biodiesel production.

\subsection{Performance of Catalyst for Biodiesel Production}

3.3.1. The Effect of Catalyst Loading. The production of biodiesel yield was done by evaluating the percentage performance of the CBA blended catalyst using (1), by changing the conditions of the parameters of the reaction like percentage by weight of the catalyst added, the reaction timetemperature set, and the ratio of methanol and neem oil used. The amount of produced biodiesel was affected by the amount of the catalyst. The excess ratio of $16: 1$ of methanol to oil was used during testing the performance of the catalyst. The amount of catalyst added varied with the amount of oil at an interval of $0.1 \mathrm{wt} \%$ from 1 to $2 \mathrm{wt} \%$. The effect of catalyst loaded on the rate of production of biodiesel yield was increased from 1.1 to $1.7 \mathrm{wt} \%$, respectively, whereby the percentage of conversion of biodiesel was increased. The highest production yields $98.8 \%$ of biodiesel were attained at catalyst to oil weight of $1.7 \mathrm{wt} \%$ as shown in Figure 5. Several factors might have contributed to the high production yield of biodiesel, for example, the high surface area of the catalyst and presence of basic metal oxides such as $\mathrm{K}, \mathrm{Na}, \mathrm{Ca}$, and $\mathrm{Mg}$, which contributed to high basic strength 11.1 of the catalyst. Also, the availability of higher oxygen compounds in $\mathrm{Li}-\mathrm{CaO} / \mathrm{Fe}_{2}\left(\mathrm{SO}_{4}\right)_{3}$ increases the rate of conversion methyl ester to biodiesel $[42,43]$.

3.3.2. Effect of Reaction Time. Production of biodiesel increases with the increase of time of the reaction [44]. The conversion rate of biodiesel depends on the time response for the required chemical reaction to take place [45]. The production biodiesel using NSO with $1.7 \mathrm{wt} \%$ catalyst loading and 8:1 excess methanol was done by changing the time of the reaction after every $10 \mathrm{~min}$ from 10 to $70 \mathrm{~min}$ while stirring at $2700 \mathrm{rpm}$ and maintaining the temperature at $60^{\circ} \mathrm{C}$. Figure 6 shows the effects of time on biodiesel yield. It is observed that the rate of production of biodiesel yield increases with time from $10 \mathrm{~min}$ to around $50 \mathrm{~min}$. Above $50 \mathrm{~min}$, biodiesel yield remained constant. This is due to a reversible reaction caused by the reduced and disappearance of esters resulting in soap formation associated with the fatty acid composition [46]. It observed that the proper time for the production of the highest yield of biodiesel is $53 \mathrm{~min}$.

3.3.3. The Effect of Methanol-to-Oil Ratio. Key factors for converting long fatty acid esters to methyl esters (biodiesel) are the ratio of methanol to oil. The relation between quantities of substance and the number of moles that can take part in a chemical reaction is needed in the process [33]. This can result in the split of the mixture of reaction on the solubility of glycerol to the methyl ester layer. Figure 7 shows that the best ratio that can be seen as methanol-to-oil ratio of $8: 1$ highest yield of biodiesel was attained. This intensifies the equilibrium reaction which may affect the production biodiesel yield [46].

3.4. Catalyst Recyclability. Bio-based catalyst precursor prepared was reused up to the fifth run in the transesterification process, under the optimum condition, $1.7 \mathrm{wt}$ $\%$ catalyst feed, methanol-to-oil molar ratio $8: 1,53 \mathrm{~min}$ time of the reaction, $60^{\circ} \mathrm{C}$ temperatures of the reaction, and stirring rate of $2700 \mathrm{rpm}$. From Figure 8, one can see that catalyst performance in biodiesel yield decreased in every successive route. The yield was as follows: 98.8, 96.7, 85.7, 82.8 , and $75.6 \%$ in the first, second, third, fourth, and fifth run, respectively. This may be due to the loss of functional groups of the catalyst. The loss of the catalyst active site may be due to $\mathrm{H}_{2} \mathrm{O}$ and $\mathrm{CO}_{2}$ from the environments. Recyclability of the catalyst numerously shows the great significance of the bio-based catalyst in minimizing waste disposal and 
TABle 3: Fatty acid composition of neem oil.

\begin{tabular}{|c|c|c|c|c|}
\hline Fatty acid & Formula & Systematic name & Structure & wt.(\%) \\
\hline \multicolumn{5}{|c|}{ Saturated fatty acids } \\
\hline Palmitic & $\mathrm{C}_{16} \mathrm{H}_{32} \mathrm{O}_{2}$ & Hexadecanoic acid & $16: 0$ & 10.92 \\
\hline Stearic & $\mathrm{C}_{18} \mathrm{H}_{36} \mathrm{O}_{2}$ & (E)-9-Octadecenoic acid & $18: 1$ & 19.85 \\
\hline Arachidic & $\mathrm{C}_{20} \mathrm{H}_{40} \mathrm{O}_{2}$ & Eicosanoic acid & 20.0 & 1.35 \\
\hline Lignoceric & $\mathrm{C}_{24} \mathrm{H}_{48} \mathrm{O}_{2}$ & Tetracosanoic acid & 24.0 & 0.26 \\
\hline Total & & & & 32.38 \\
\hline \multicolumn{5}{|c|}{ Unsaturated fatty acids } \\
\hline Pentadecanoic & $\mathrm{C}_{17} \mathrm{H}_{34} \mathrm{O}_{2}$ & Pentadecanoic acid, 14 & $17: 1$ & 2.57 \\
\hline Oleic & $\mathrm{C}_{18} \mathrm{H}_{34} \mathrm{O}_{2}$ & 9-Octadecenoic acid & $18: 1$ & 1.82 \\
\hline Linoleic & $\mathrm{C}_{18} \mathrm{H}_{32} \mathrm{O}_{2}$ : & 9,12-Octadecadienoic acid & $18: 1$ & 52.51 \\
\hline Linolenic & $\mathrm{C}_{18} \mathrm{H}_{30} \mathrm{O}_{2}$ & 9,12-Octadecatrienoic acid & $18: 1$ & 10.71 \\
\hline Total & & & & 67.62 \\
\hline
\end{tabular}

TABle 4: Physicochemical properties of neem biodiesel.

\begin{tabular}{lccc}
\hline Test/characteristics & Petrol diesel ASTM D975 limits & Biodiesel ASTM D 6751 limits & Biodiesel \\
\hline Density at $15 \mathrm{~kg} / \mathrm{m}^{3}$ & 850 & $860-900$ & 863.8 \\
Kinematics viscosity at $40^{\circ} \mathrm{C}\left(\mathrm{mm}^{2} / \mathrm{s}\right)$ & $2-4.5$ & $1.9-6.0$ & $\mathrm{NS}$ \\
Pour point $\left({ }^{\circ} \mathrm{C}\right)$ & -35 to -15 & $130 \mathrm{~min}$ & -30 \\
Flashpoint $\left({ }^{\circ} \mathrm{C}\right)$ & $60-80$ & $\mathrm{NS}$ & 150 \\
Cloud point $\left({ }^{\circ} \mathrm{C}\right)$ & -15 to -5 & 47 & $\mathrm{NS}$ \\
Cetane index $($ minimum $)$ & - & $\mathrm{NS}$ & 48.9 \\
Initial boiling point $\left({ }^{\circ} \mathrm{C}\right)$ & - & - & 86 \\
Final boiling point $\left({ }^{\circ} \mathrm{C}\right)$ & - & $0.5 \mathrm{max}$ \\
Calorific value & $42-46$ & 86 \\
Acid value (titration) $(\mathrm{mgKOH} / \mathrm{g})$ & - & 43 \\
\hline
\end{tabular}

TABLE 5: Comparison of the different performance of catalyst for biodiesel production.

\begin{tabular}{|c|c|c|c|c|c|c|c|c|}
\hline $\begin{array}{l}\text { Heterogeneous } \\
\text { catalyst type }\end{array}$ & Feedstock & $\begin{array}{l}\text { Surface area } \\
\qquad\left(\mathrm{m}^{2} / \mathrm{g}\right)\end{array}$ & $\begin{array}{c}\text { Catalyst dosage } \\
\text { (wt.\%) }\end{array}$ & $\begin{array}{l}\text { Alcohol/oil } \\
\text { ratio }\end{array}$ & $\begin{array}{l}\text { Temp } \\
\left({ }^{\circ} \mathrm{C}\right)\end{array}$ & $\begin{array}{l}\text { Time } \\
(\mathrm{min})\end{array}$ & $\begin{array}{l}\text { Yield } \\
\text { (wt.\%) }\end{array}$ & Reference \\
\hline Banana peels & $\begin{array}{l}\text { Napoleon's } \\
\text { plumule oil }\end{array}$ & 4.44 & 2.75 & $30: 1$ & 65 & 69.02 & 98.50 & {$[15]$} \\
\hline Banana peels & Waste cooking oil & 14.036 & 2 & $9: 1$ & 60 & 80 & 96.3 & [16] \\
\hline CBA & Neem seed oil & 411.2 & 1.7 & 8.1 & 60 & 53 & 98.80 & This study \\
\hline
\end{tabular}

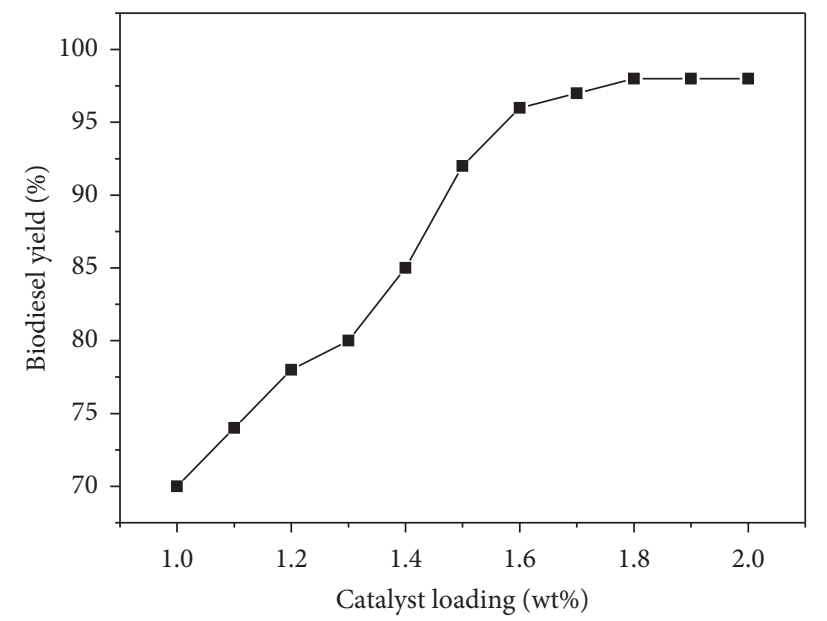

Figure 5: Effect of the amount of catalyst added on the production of biodiesel. 


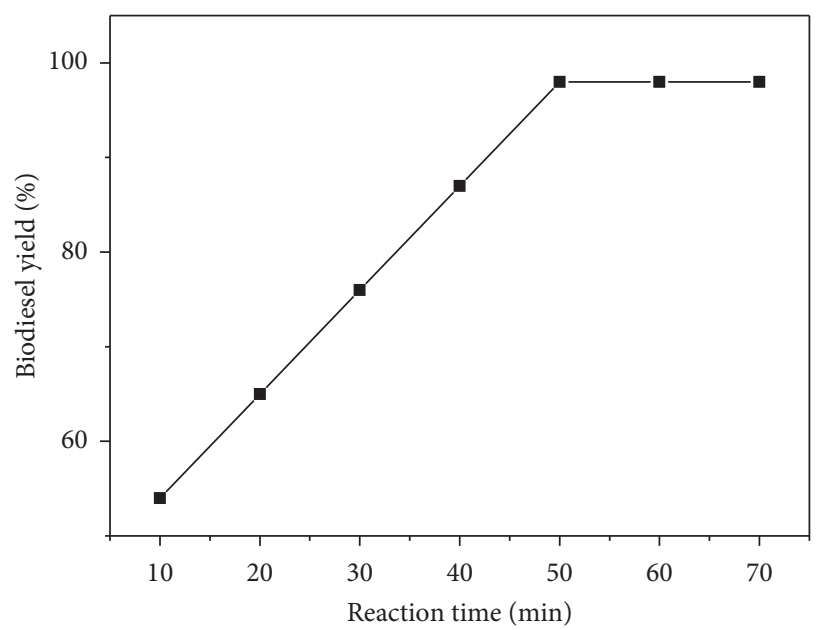

Figure 6: Effect of reaction time on biodiesel yield.

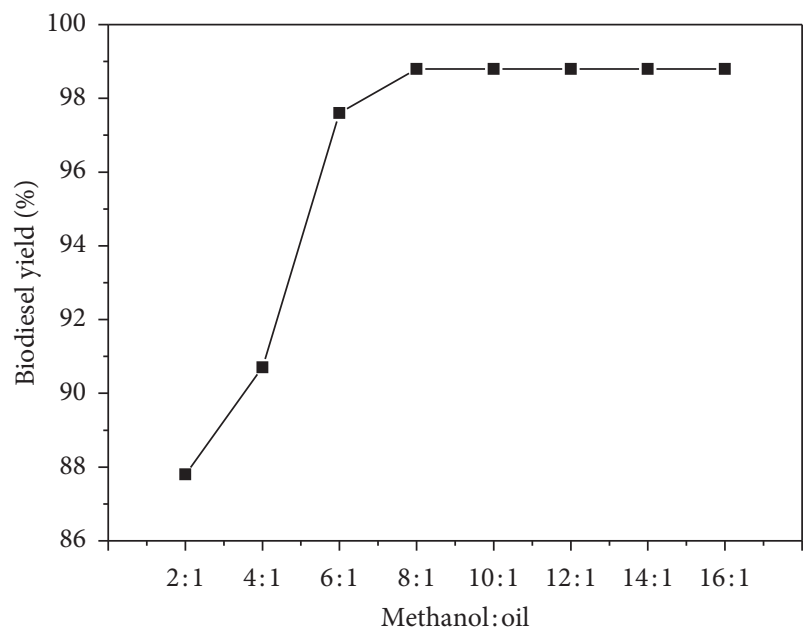

Figure 7: Effect of the ratio of methanol and oil on a yield of biodiesel.

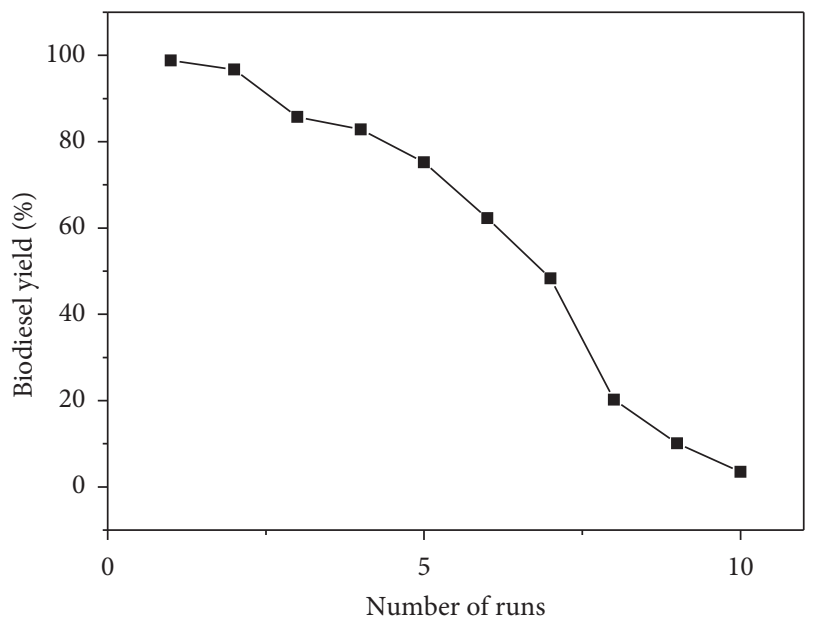

FIgURE 8: The recyclability catalyst versus \% of biodiesel production. production expenses and is environmentally friendly during the production of biodiesel.

\section{Conclusion}

This study presents the production of biodiesel from NSO and affordable solid catalyst synthesized by direct calcination of banana peels. Calcined banana peels at $650^{\circ} \mathrm{C}$ acquired good catalytic activity due to the presence of basic metal oxides of $\mathrm{K}, \mathrm{Ca}, \mathrm{Na}$, and $\mathrm{Mg}$ and basic strength of 11.09. The performance was also attributed to its high specific surface area of $411 \mathrm{~m}^{2} / \mathrm{g}$ and pore diameter of $3.0 \mathrm{~nm}$. The maximum biodiesel production yield of $98.8 \%$ was achieved at a low catalyst loading of $1.7 \mathrm{wt} \%$ and $8: 1$ methanol-to-oil molar ratio at a temperature of $60^{\circ} \mathrm{C}$. The produced biodiesel acquired physicochemical parameters within the recommended ASTM D6751 standards and it displayed remarkable cold flow properties, that is, cloud point, pour point, and kinematic viscosity, and may be used in cold areas; also the calorific value was high. The catalyst shows good reusability properties with a yield of approximately $75 \%$ after a fifth run. It can be concluded that the produced CBA catalyst minimizes waste disposal, hence standing out as an environmentally compatible catalyst.

\section{Data Availability}

The data used to support the findings of this study are available from the corresponding author upon request.

\section{Conflicts of Interest}

The authors declare that there are no conflicts of interest in this work.

\section{Authors' Contributions}

All the authors have approved the manuscript.

\section{Acknowledgments}

The authors acknowledge the financial support from Water Infrastructure and Sustainable Energy Futures (WISE-Futures) and other supports from the Nelson Mandela African Institution of Science and Technology (NM-AIST) and The World Academy of Science (TWAS).

\section{Supplementary Materials}

Figure S1 shows procedures for preparation of calcined banana ash (CBA) catalyst. This was done by slicing the banana peel followed by sun drying then oven drying and finally calcination at $650^{\circ} \mathrm{C}$ to obtain the required catalyst. Figure S2 shows procedures for extraction of oil from neem seed. Neem seed oil was extracted using a hydraulic pressing machine. Neem seeds were fed to the machine and then pressed to produce oil. Figure S3 shows biodiesel production steps through transesterification process using CBA loaded with metal oxide ( $\mathrm{Li}-\mathrm{CaO} / \mathrm{Fe}_{2}\left(\mathrm{SO}_{4}\right)_{3}$ as a catalyst. (Supplementary Materials) 


\section{References}

[1] A. K. Endalew and Y. Kiros, "Catalytic autoxidation of fatty acid methyl esters from jatropha oil," Journal of Fuels, vol. 2014, Article ID 470790, 6 pages, 2014.

[2] A. L. Ahmad, N. H. M. Yasin, C. J. C. Derek, and J. K. Lim, "Microalgae as a sustainable energy source for biodiesel production: a review," Renewable and Sustainable Energy Reviews, vol. 15, no. 1, pp. 584-593, 2011.

[3] L. C. Meher, D. V. Sagar, and S. Naik, "Technical aspects of biodiesel production by transesterification-a review," Renewable and Sustainable Energy Reviews, vol. 10, no. 3, pp. 248-268, 2006.

[4] S. V. Ghadge and H. Raheman, "Process optimization for biodiesel production from mahua (Madhuca indica) oil using response surface methodology," Bioresource Technology, vol. 97, no. 3, pp. 379-384, 2006.

[5] L. Coniglio, H. Bennadji, P. A. Glaude, O. Herbinet, and F. Billaud, "Combustion chemical kinetics of biodiesel and related compounds (methyl and ethyl esters): experiments and modeling-advances and future refinements," Progress in Energy and Combustion Science, vol. 39, no. 4, pp. 340-382, 2013.

[6] M. J. Ramos, C. M. Fernández, A. Casas, L. Rodríguez, and Á. Pérez, "Influence of fatty acid composition of raw materials on biodiesel properties," Bioresource Technology, vol. 100, no. 1, pp. 261-268, 2009.

[7] M. M. Gui, K. T. Lee, and S. Bhatia, "Feasibility of edible oil vs. non-edible oil vs. waste edible oil as biodiesel feedstock," Energy, vol. 33, no. 11, pp. 1646-1653, 2008.

[8] G. Antolın, "Optimisation of biodiesel production by sunflower oil transesterification," Bioresource Technology, vol. 83, no. 2, pp. 111-114, 2002.

[9] E. Crabbe, C. Nolasco-Hipolito, G. Kobayashi, K. Sonomoto, and A. Ishizaki, "Biodiesel production from crude palm oil and evaluation of butanol extraction and fuel properties," Process Biochemistry, vol. 37, no. 1, pp. 65-71, 2001.

[10] B. K. Barnwal and M. P. Sharma, "Prospects of biodiesel production from vegetable oils in India," Renewable and Sustainable Energy Reviews, vol. 9, no. 4, pp. 363-378, 2005.

[11] A. E. Atabani, A. S. Silitonga, H. C. Ong et al., "Non-edible vegetable oils: a critical evaluation of oil extraction, fatty acid compositions, biodiesel production, characteristics, engine performance and emissions production," Renewable and Sustainable Energy Reviews, vol. 18, pp. 211-245, 2013.

[12] H. Schmutterer, "Properties and potential of natural pesticides from the neem tree, Azadirachta indica," Annual Review of Entomology, vol. 35, no. 1, pp. 271-297, 1990.

[13] S. K. Kaura, S. K. Gupta, and J. B. Chowdhury, "Morphological and oil content variation in seeds of Azadirachta indica A. Juss. (neem) from northern and western provenances of India," Plant Foods for Human Nutrition, vol. 52, no. 4, pp. 293-298, 1998.

[14] V. S. Kumar and V. Navaratnam, "Neem (Azadirachta indica): prehistory to contemporary medicinal uses to humankind," Asian Pacific Journal of Tropical Biomedicine, vol. 3, no. 7, pp. 505-514, 2013.

[15] E. Betiku, A. M. Akintunde, and T. V. Ojumu, "Banana peels as a biobase catalyst for fatty acid methyl esters production using Napoleon's plume (Bauhinia monandra) seed oil: a process parameters optimization study," Energy, vol. 103, pp. 797-806, 2016.

[16] M. Gohain, A. Devi, and D. Deka, "Musa balbisiana colla peel as highly effective renewable heterogeneous base catalyst for biodiesel production," Industrial Crops and Products, vol. 109, pp. 8-18, 2017.

[17] P. Onwuachi-Iheagwara, "Comparative analysis of the use of banana peels and $\mathrm{NaOH}$ in $\mathrm{Ph}$ control in Nigerian clays," Journal of the Nigerian Association of Mathematical Physics, vol. 30, pp. 197-202, 2015.

[18] E. G. N. Mbanjo, F. Tchoumbougnang, A. S. Mouelle et al., "Molecular marker-based genetic linkage map of a diploid banana population (Musa acuminata colla)," Euphytica, vol. 188, no. 3, pp. 369-386, 2012.

[19] A. M. Khan, S. Khaliq, and R. Sadiq, "Investigation of waste banana peels and radish leaves for their biofuels potential," Bulletin of the Chemical Society of Ethiopia, vol. 29, no. 2, pp. 239-245, 2015.

[20] N. Z. Dimetry, S. Amer, and A. S. Amer, "Biological activity of two neem seed kernel extracts against the two-spotted spider mite Tetranychus urticae Koch," Journal of Applied Entomology, vol. 116, no. 1-5, pp. 308-312, 1993.

[21] N. B. Kyriakidis and T. Katsiloulis, "Calculation of iodine value from measurements of fatty acid methyl esters of some oils: comparison with the relevant American oil chemists society method," Journal of the American Oil Chemists' Society, vol. 77, no. 12, pp. 1235-1238, 2000.

[22] Y. A. Elsheikh, "Preparation of Citrullus colocynthis biodiesel via dual-step catalyzed process using functionalized imidazolium and pyrazolium ionic liquids for esterification step," Industrial Crops and Products, vol. 49, pp. 822-829, 2013.

[23] A. Abbaszaadeh, "Current biodiesel production technologies: a comparative review," Energy Conversion and Management, vol. 63, pp. 138-148, 2012.

[24] M. Xiao, S. Mathew, and J. P. Obbard, "Biodiesel fuel production via transesterification of oils using lipase biocatalyst," Gcb Bioenergy, vol. 1, no. 2, pp. 115-125, 2009.

[25] M. Elkady, A. Zaatout, and O. Balbaa, "Production of biodiesel from waste vegetable oil via KM micromixer," Journal of Chemistry, vol. 2015, Article ID 630168, 9 pages, 2015.

[26] H. Ibrahim, "Advancement in heterogeneous catalysis of triglycerides for biodiesel production," International Journal of Engineering and Computer Science, vol. 2, no. 5, pp. 1426-1433, 2013.

[27] Z. Zhang, S. Yang, M. Dou, H. Liu, L. Gu, and F. Wang, "Systematic study of transition-metal (Fe, Co, $\mathrm{Ni}, \mathrm{Cu}$ ) phthalocyanines as electrocatalysts for oxygen reduction and their evaluation by DFT," RSC Advances, vol. 6, no. 71, pp. 67049-67056, 2016.

[28] N. Iwamoto, "Melting points of inorganic fluorides," Transactions of JWRI, vol. 2, no. 2, pp. 204-207, 1973.

[29] M. Zabeti, W. M. A. W. Daud, and M. K. Aroua, "Activity of solid catalysts for biodiesel production: a review," Fuel Processing Technology, vol. 90, no. 6, pp. 770-777, 2009.

[30] J. R. Memon, S. Q. Memon, M. I. Bhanger, G. Z. Memon, A. El-Turki, and G. C. Allen, "Characterization of banana peel by scanning electron microscopy and FT-IR spectroscopy and its use for cadmium removal," Colloids and Surfaces B: Biointerfaces, vol. 66, no. 2, pp. 260-265, 2008.

[31] M. Sharma, A. A. Khan, S. K. Puri, and D. K. Tuli, "Wood ash as a potential heterogeneous catalyst for biodiesel synthesis," Biomass and Bioenergy, vol. 41, pp. 94-106, 2012.

[32] E. Betiku, A. O. Etim, O. Pereao, and T. V. Ojumu, "Two-step conversion of neem (Azadirachta indica) seed oil into fatty methyl esters using a heterogeneous biomass-based catalyst: an example of cocoa pod husk," Energy \& Fuels, vol. 31, no. 6, pp. 6182-6193, 2017. 
[33] H. J. Berchmans and S. Hirata, "Biodiesel production from crude Jatropha curcas L. seed oil with a high content of free fatty acids," Bioresource Technology, vol. 99, no. 6, pp. 1716-1721, 2008.

[34] C. Martín, A. Moure, G. Martín, E. Carrillo, H. Domínguez, and J. C. Parajó, "Fractional characterisation of jatropha, neem, moringa, trisperma, castor and candlenut seeds as potential feedstocks for biodiesel production in Cuba," Biomass and Bioenergy, vol. 34, no. 4, pp. 533-538, 2010.

[35] L. Niu, J. Li, M.-S. Chen, and Z.-F. Xu, "Determination of oil contents in Sacha inchi (Plukenetia volubilis) seeds at different developmental stages by two methods: soxhlet extraction and time-domain nuclear magnetic resonance," Industrial Crops and Products, vol. 56, pp. 187-190, 2014.

[36] F. Kusu, T. Fuse, and K. Takamura, "Voltammetric determination of acid values of fats and oils," Journal of AOAC International, vol. 77, no. 6, pp. 1686-1688, 1994.

[37] S. Dileesh, Determination of Saponification, Acid and Ester Values; Percentage of Free Fatty Acids and Glycerol in Some Selected Edible Oils: Calculation of Concentration of Lye Needed to Prepare Soap from these Oils, Scholars Association of Kerala, Kottayam, Kerala, 2013.

[38] D. E. Bowyer, W. M. F. Leat, A. N. Howard, and G. A. Gresham, "The determination of the fatty acid composition of serum lipids separated by thin-layer chromatography; and a comparison with column chromatography," Biochimica et Biophysica Acta, vol. 70, pp. 423-431, 1963.

[39] H. Muthu, V. SathyaSelvabala, T. K. Varathachary, D. Kirupha Selvaraj, J. Nandagopal, and S. Subramanian, "Synthesis of biodiesel from neem oil using sulfated zirconia via tranesterification," Brazilian Journal of Chemical Engineering, vol. 27, no. 4, pp. 601-608, 2010.

[40] H. Ong et al., "Production and comparative fuel properties of biodiesel from non-edible oils: jatropha curcas, Sterculia foetida and Ceiba pentandra," Energy Conversion and Management, vol. 73, pp. 245-255, 2013.

[41] J. Blin, C. Brunschwig, A. Chapuis et al., "Characteristics of vegetable oils for use as fuel in stationary diesel enginesTowards specifications for a standard in West Africa," Renewable and Sustainable Energy Reviews, vol. 22, pp. 580-597, 2013.

[42] F. Guo, Z.-G. Peng, J.-Y. Dai, and Z.-L. Xiu, "Calcined sodium silicate as solid base catalyst for biodiesel production," Fuel Processing Technology, vol. 91, no. 3, pp. 322-328, 2010.

[43] L. Buchori, I. Istadi, and P. Purwanto, "Advanced chemical reactor technologies for biodiesel production from vegetable oils-a review," Bulletin of Chemical Reaction Engineering \& Catalysis, vol. 11, no. 3, pp. 406-430, 2016.

[44] H. He, T. Wang, and S. Zhu, "Continuous production of biodiesel fuel from vegetable oil using supercritical methanol process," Fuel, vol. 86, no. 3, pp. 442-447, 2007.

[45] B. Jenkins et al., "Combustion properties of biomass," Fuel Processing Technology, vol. 54, no. 1-3, pp. 17-46, 1998.

[46] A. Ramadhas, S. Jayaraj, and C. Muraleedharan, "Biodiesel production from high FFA rubber seed oil," Fuel, vol. 84, no. 4 , pp. 335-340, 2005. 